\title{
O PRINCÍPIO DA PRECAUÇÃO E A AVALIAÇÃO PRÉVIA DE IMPACTO AMBIENTAL: A POSIÇÃO DO SUPERIOR TRIBUNAL DE JUSTIÇA
}

\section{THE PRECAUTIONARY PRINCIPLE AND THE PREVIOUS ENVIRONMENTAL IMPACT ASSESSMENT: THE POSITION OF THE SUPERIOR COURT OF JUSTICE}

Débora Hartmann

Bacharel em Direito pela Universidade de Caxias do Sul (UCS). Pesquisadora do Grupo de Pesquisa CNPq "Cultura Política, Políticas Públicas e Sociais".

E-mail: deborahartmann.deh@gmail.com

Leonardo da Rocha de Souza

Pós-doutorando em Direito (UFRGS). Doutor e Mestre em Direito (UFRGS). Bacharel em Direito (UNISINOS). Especialista em Ética e Filosofia Política (UCS). Diplomado pela Escola Superior da Magistratura (AJURIS). Procurador do Município de Caxias do SulRS. Professor Adjunto da Universidade de Caxias do Sul, com atuação na graduação em Direito e no Programa de Pós-graduação Stricto Sensu em Direito como membro do corpo permanente. Pesquisador do Grupo de Pesquisa CNPq "Cultura Política, Políticas Públicas e Sociais". E-mail: leorochasouza@gmail.com

Recebido em: 15/09/2016

Aprovado em: 30/11/2016

Doi: $10.5585 /$ rdb.v16i7.482

RESUMO: O princípio da precaução é invocado em situações nas quais não haja certeza científica da segurança de determinada atividade ou empreendimento, bem como, dos riscos e da extensão dos riscos que possam advir dessa atividade. Por isso, sua aplicação exige dos empreendimentos uma prévia avaliação do impacto ambiental. O objetivo deste artigo é entender como tem sido aplicado o princípio da precaução nas decisões colegiadas do Superior Tribunal de Justiça, especificamente quando esse princípio é utilizado como fundamento para exigir a avaliação prévia de impacto ambiental. Para isso, foram analisados os acórdãos do STJ que versam sobre essa temática, utilizando-se o método de abordagem indutivo e as técnicas de pesquisa de revisão bibliográfica e estudo de casos. Como resultado, percebeu-se que a aplicação do princípio da precaução realizada pelo STJ vem se consolidando, especialmente para reduzir o risco de danos, mas que ainda precisa de avanços para alcançar completamente os fins a que se destina.

Palavras-chave: Princípio da precaução. Risco. Meio ambiente. Impacto ambiental. Gestão ambiental.

ABSTRACT: The precautionary principle is used in situations in which there is no scientific certainty about the safety of an activity or project, as well as the risks and extent of risks which may result from this activity. Therefore, its implementation requires the projects a previous environmental impact assessment. The purpose of this article is to understand how the precautionary principle has been applied in the collegiate decisions of the Superior Court of Justice, specifically when this principle is used as a basis for requiring a previous environmental 
impact assessment. For this, the judgments of the Supreme Court that deal with this subject were analyzed using the inductive method of approach and the literature review of research techniques and case studies. As a result, it was noted that the application of the precautionary principle held by the Superior Court of Justice has consolidated, especially to reduce the risk of damage, but it still needs improvements to fully achieve the purpose for which it is intended.

Keywords: Precautionary Principle. Risk. Environment. Environmental impact. Environmental management.

SUMÁRIO: Introdução. 1 Aspectos gerais sobre o princípio da precaução. 2 O risco do dano como fundamento para a exigência da avaliação prévia de impacto ambiental. 3 A posição do Superior Tribunal de Justiça a respeito da necessidade de avaliação prévia de impacto ambiental frente ao princípio da precaução. 3.1 Metodologia. 3.2 Análise das decisões. Conclusão. Referências.

\section{INTRODUÇÃO}

O objetivo deste artigo é verificar a forma como o Superior Tribunal de Justiça (STJ) tem aplicado o princípio da precaução em suas decisões colegiadas, especialmente no que se refere à avaliação prévia de impacto ambiental. Assim, o problema de pesquisa resulta na seguinte questão: que parâmetros são adotados pelo STJ quando utiliza o princípio da precaução como fundamento para exigir a avaliação prévia de impacto ambiental?

Verifica-se, em uma análise prévia, que é comum o princípio da precaução ser aplicado sem que seja observada sua principal finalidade. Algumas vezes é confundido com o princípio da prevenção, outras vezes é aplicado sem a devida fundamentação. A avaliação prévia de impacto ambiental, por exemplo, deveria sempre ser exigida quando uma atividade está relacionada à existência de riscos sérios e irreversíveis ao meio ambiente e à saúde humana. É possível, assim, que haja eventuais enganos jurídicos na interpretação e na aplicação do princípio da precaução.

O método utilizado neste artigo é o indutivo, partindo-se da análise de casos (particular) para descobrir o entendimento jurisprudencial (geral) por meio da análise de acórdãos do Superior Tribunal de Justiça que utilizem o princípio da precaução como fundamento para exigir a avaliação prévia de impacto ambiental, buscando-se encontrar um parâmetro operacional desse princípio.

As técnicas utilizadas envolvem, inicialmente, a pesquisa bibliográfica a partir de referenciais teóricos que indicam o conceito e os elementos identificadores do princípio da precaução, bem como o estudo de casos por meio da análise crítica das decisões judiciais encontradas.

A estrutura deste artigo inicia com um estudo geral sobre princípios de Direito Ambiental e sua importância, com ênfase no princípio da precaução (item 1). Depois, restringe-se a análise a um dos elementos do princípio da precaução, o risco do dano, verificando-se de que forma ele pode ser o fundamento para a exigência da avaliação prévia de impacto ambiental (item 2). Esses tópicos são preparatórios para o item 3, parte principal deste artigo, no qual se planeja encontrar a posição do Superior Tribunal de Justiça a respeito da necessidade de avaliação prévia de impacto ambiental frente ao princípio da precaução. Esse item 3 inicia com um detalhamento a respeito da metodologia (3.1) e segue com a efetiva análise das decisões (3.2). 


\section{ASPECTOS GERAIS SOBRE O PRINCÍPIO DA PRECAUÇÃO}

O Direito Ambiental ${ }^{1}$, área relativamente nova do Direito, vem construindo seu espaço, no Brasil e no mundo, como importante aliado na preservação dos bens naturais, da fauna e da flora mundial, do solo, das águas e do patrimônio genético ambiental. É um instrumento de ação, seja de ação positiva (fazer), ou negativa (deixar de fazer) de acordo com a situação em que venha a ser aplicado. Sua importância se deve ao fato de ser ele uma ferramenta que, quando observada pelo Estado e pela sociedade, pode se tornar aliado na preservação, no gerenciamento e na proteção dos bens ambientais necessários à qualidade de vida das presentes e futuras gerações.

O Direito Ambiental tem se mostrado cada vez mais preocupado com a utilização de bens naturais, como destaca Antunes, em uma análise com foco na atividade econômica:

A preocupação fundamental do Direito Ambiental é organizar a utilização social dos recursos ambientais, estabelecendo métodos, critérios, proibições e permissões, definindo o que pode e o que não pode ser apropriado economicamente (ambientalmente). Não satisfeito, vai além. Ele estabelece como a apropriação econômica (ambiental) pode ser feita. Logo, o Direito Ambiental se encontra no coração de toda atividade econômica, pois qualquer atividade econômica se faz sobre a base de uma infraestrutura que consome recursos naturais, notadamente sob a forma de energia. ${ }^{2}$

O Direito Ambiental não preconiza, assim, a paralisação do desenvolvimento, do avanço da tecnologia, ou mesmo o retrocesso econômico. Pelo contrário, cria critérios, métodos e bases para que o crescimento econômico e social permaneça numa constante. A preservação ambiental, aliada ao desenvolvimento econômico e social, onde desde o início dos projetos não seja possível separar um do outro, leva ao desenvolvimento sustentável ${ }^{3}$. Ingo Wolfgang Sarlet e Tiago Fensterseifer vão além e falam de um possível Estado Socioambiental do Direito ${ }^{4}$, que pressupõe um Estado regulador da atividade econômica, que insere valores e princípios constitucionais, ajustando a economia a esses valores, tendo como objetivo o desenvolvimento humano e social de forma ambientalmente saudável.

A problemática das questões ambientais ganhou importância global e passou assim, a viabilizar relevantes discussões acerca do tema, na tentativa de encontrar-se um consenso, um ponto de equilíbrio na relação econômico-ambiental.

Buscando regulamentar a relação do homem com o meio ambiente em que está inserido, o Direito se utiliza de leis, normas, resoluções, tratados, doutrina, jurisprudência e princípios para qualificar e proteger essa relação. Na tentativa de preencher os espaços deixados pelas normas, o Direito se utiliza de instrumentos jurídicos, como os princípios. Objetivando uma melhor

\footnotetext{
1 “[...] é o complexo de princípios e normas coercitivas reguladoras das atividades humanas que, direta ou indiretamente, possam afetar a sanidade do ambiente em sua dimensão global, visando à sua sustentabilidade para as presentes e futuras gerações". (MILARÉ, Édis. Direito do Ambiente. 9. ed. São Paulo: Revista dos Tribunais, 2014, p. 256-257).

2 ANTUNES, Paulo de Bessa. Direito Ambiental. 16. ed. São Paulo: Atlas, 2014, p. 3.

3 "Por isso, nos últimos anos, a sociedade vem acordando (embora lentamente) para a problemática ambiental. O mero crescimento econômico, mito generalizado, vem sendo repensado em alternativas, como o eco desenvolvimento ou o desenvolvimento sustentável, cuja característica principal consiste na possível e desejável conciliação entre o desenvolvimento integral, a preservação do meio ambiente e a melhoria na qualidade de vida três metas indispensáveis. Crescimento econômico, tão só, mais do que pouco é desastroso". (MILARÉ, Direito do Ambiente, p. 59).

${ }^{4}$ SARLET, Ingo Wolfgang; FENSTERSEIFER, Tiago. Direito Constitucional Ambiental: Constituição, Direitos Fundamentais e Proteção do Ambiente. 4. ed. São Paulo: Revista dos Tribunais, 2014, p. 127.
}

Revista de Direito Brasileira | São Paulo, SP | v. 16 | n. 7 | p. 151 - 168 | Jan./Abr. 2017 
adequação ao caso concreto e uma correta análise jurídica da situação para que se chegue a um ponto mais próximo possível de um resultado efetivamente justo, é que o Direito, precisamente, possui outras fontes de respaldo.

Os princípios ${ }^{5}$ são importantes fontes do Direito, sendo responsáveis por nortear a criação de leis e por embasar decisões jurídicas, aplicando da melhor forma possível o Direito ao caso concreto. Os princípios são a base jurídica, seja qual for a vertente a ser observada.

Dessa forma, no Direito Ambiental existem importantes princípios, tais como: o princípio do poluidor-pagador e usuário-pagador; o princípio do desenvolvimento sustentável; o princípio da equidade intergeracional; o princípio da supremacia do interesse público na proteção do meio ambiente; o princípio da função socioambiental; o princípio da prevenção; e o princípio da precaução, objeto de análise deste texto, entre outros que variam em decorrência da ampliação dos entendimentos doutrinários.

O princípio da precaução tem por objetivo evitar a ocorrência de danos irreversíveis ou irreparáveis, advindos de uma situação de incerteza científica acerca da possibilidade de riscos na produção de danos. Age-se de antemão para que resultados negativos não ocorram. Neste caso, antes que se verifique o dano é necessária uma postura de precaução, tendo em vista que danos ambientais produzem consequências irreparáveis ou que somente após um longo lapso temporal há recuperações totais ou parciais do ambiente degradado. ${ }^{6}$ Como ensina Leme Machado, a precaução deve ajudar a "impedir o prejuízo ambiental, mesmo incerto, que possa resultar das ações ou omissões humanas", bem como "deve atuar na prevenção oportuna desse prejuízo. [...] Na dúvida, opta-se pela solução que proteja imediatamente o ser humano e conserve o meio ambiente". 7

O Princípio 15 da Declaração da Conferência Rio-92 é o marco de grande importância e de reconhecimento internacional na aplicação do princípio da precaução, e estabelece que:

Com o fim de proteger o meio ambiente, o princípio da precaução deverá ser amplamente observado pelos Estados, de acordo com suas capacidades. Quando houver ameaça de danos graves ou irreversíveis, a ausência de certeza científica não será utilizada como razão para o adiamento de medidas economicamente viáveis para prevenir a degradação ambiental. ${ }^{8}$

Há outro tratado internacional internalizado pelo Brasil por meio do Decreto Legislativo $\mathrm{n}^{\circ} 1$, de 03 de fevereiro de 1994, e que consagra o princípio da precaução, a Convenção-Quadro das Nações Unidas Sobre Mudança do Clima, que, em seu artigo 3, prevê que os países signatários adotem "medidas de precaução para prever, evitar ou minimizar as causas da mudança do clima e mitigar seus efeitos negativos. Quando surgirem ameaças de danos sérios ou irreversíveis, a falta de plena certeza científica não deve ser utilizada como razão para postergar essas medidas."

\footnotetext{
${ }^{5}$ “[...] no empenho natural de legitimar o Direito do Ambiente como ramo especializado e peculiar da árvore da ciência jurídica, têm os estudiosos se debruçado sobre a identificação dos princípios ou mandamentos básicos que fundamentam o desenvolvimento da doutrina e que dão consistência às suas concepções.[...] A palavra princípio, em sua raiz latina, significa "aquilo que se toma primeiro" (primum capere), designado início, começo, ponto de partida”. (MILARÉ, Édis. Direito do Ambiente. 9. ed. São Paulo: Revista dos Tribunais, 2014. p. 258).

WEDY, Gabriel de Jesus Tedesco. Os Fundamentos do Princípio da Precaução. Juris Plenum Direito Administrativo. Ano II, número 08, out/dez 2015, p. 109-138.

${ }^{7}$ MACHADO, Paulo Affonso Leme. Direito Ambiental Brasileiro. 21. ed. São Paulo: Malheiros, 2013 p. 111.

8 Conferência das Nações Unidas sobre Meio Ambiente e Desenvolvimento de 1992. Disponível em: <http://www.mma.gov.br/port/sdi/ea/documentos/convs/decl_rio92.pdf>. Acesso em: 03/09/2016. A Declaração do Rio de Janeiro teve sua autorização para ratificação em 03 de fevereiro de 1994, através do Congresso Nacional, por meio do Decreto Legislativo no 2. Entrou em vigor no Brasil a partir de 09 de maio de 1994 e foi promulgada pelo Decreto $\mathrm{n}^{\circ} 2519$ de 16 de março de 1998.
}

Revista de Direito Brasileira | São Paulo, SP | v. 16 | n. 7 | p. 151 - 168 | Jan./Abr. 2017 
Philippe Sands relaciona diversas aplicações do princípio da precaução em contexto internacional. Critica a postura de algumas cortes por ainda relutarem contra a efetivação desse princípio e faz menção a diversos postulados internacionais que agregaram o princípio aos seus tratados e resoluções. De qualquer forma, Sands entende que "o status legal do princípio da precaução está evoluindo", já que está sendo adotado por diversos países, e "tem recebido atualmente sustentação suficientemente ampla para permitir a afirmação de que se trata de direito costumeiro. Dentro do âmbito da União Europeia, tem conseguido o status de costume internacional, mesmo com as diferentes definições adotadas". 9

O princípio da precaução é utilizado quando decisões relacionadas à preservação ambiental devem ser tomadas, notadamente em situações nas quais há incerteza sobre a potencialidade que determinada atividade possui de gerar danos. A aplicação do princípio, dessa forma, pode evitar que esses danos efetivamente aconteçam. Assim, para bem preservar é necessário precaver, em uma atuação estatal anterior ao dano. O princípio da precaução basicamente visa a proteger o meio ambiente como um todo, a fim de que as presentes e futuras gerações possam usufruir desse bem. Machado afirma que o princípio da precaução funciona como espécie de princípio in dubio pro natura ou in dubio pro salute ${ }^{10}$, ou seja, na dúvida, optase por não se colocar em risco a conservação do meio ambiente.

\section{O RISCO DO DANO COMO FUNDAMENTO PARA A EXIGÊNCIA DA AVALIAÇÃO PRÉVIA DE IMPACTO AMBIENTAL}

O princípio da precaução é composto principalmente por três importantes elementos que o caracterizam e o diferenciam dos demais e que servem para aplicar de forma correta o princípio ao caso concreto. Com base nos estudos de $\mathrm{Wedy}^{11}$, conclui-se que os principais elementos são: a incerteza científica, o risco de dano e a inversão do ônus da prova. No recorte proposto neste artigo, a ênfase será dada na existência de riscos capazes de gerar danos, que, se assumidos, podem ser devastadores para o meio ambiente e a sociedade. Por isso, é necessária uma gestão desses riscos a fim de se evitarem tais danos.

Para Wedy, o risco é proveniente da junção de dois fatores: incerteza científica e probabilidade de superveniência de um evento de consequências graves, ou a possibilidade da ocorrência de dano. ${ }^{12}$ Para evitar esses danos, é necessário que haja um adequado controle do risco à vida, à qualidade de vida e ao meio ambiente, em suma, riscos que colocam em "em perigo os valores constitucionais protegidos" na esfera ecológica. ${ }^{13}$

A Constituição Federal em seu artigo $225, \S 1^{\circ}$, IV e VII, insere o controle de riscos para a preservação do meio ambiente ecologicamente equilibrado, quando exige que o Poder Público controle "a produção, a comercialização e o emprego de técnicas, métodos e substâncias que comportem risco para a vida, a qualidade de vida e o meio ambiente" (IV), e quando determina que o Poder Público proteja a fauna e a flora impedindo "práticas que coloquem em risco sua função ecológica, provoquem a extinção de espécies ou submetam os animais a crueldade" (VII).

A complexidade das interações humanas junto à natureza e com os diversos ecossistemas mostra que não é mais possível se dar certeza da extensão das consequências dessas relações. O risco ecológico, como importante objeto do Direito Ambiental, tem se mostrado dia

\footnotetext{
${ }^{9}$ SANDS, Phillipe. O Princípio da Precaução. In: PLATIAU, Ana Flávia Barros; VARELLA, Marcelo Dias (Orgs.). O Princípio da Precaução. Editora Del Rey e Escola Superior do Ministério Público da União, s/d. Disponível em: http://www.marcelodvarella.org/meio-ambienteriscos.html. Acesso em: 03/09/2016.

${ }^{10}$ MACHADO, Paulo Affonso Leme. Direito Ambiental Brasileiro. 21. ed. São Paulo: Malheiros, 2013, p. 111.

${ }^{11}$ WEDY, Gabriel. O Princípio Constitucional da Precaução: Como instrumento de tutela do meio ambiente e da saúde pública. Belo Horizonte: Fórum, 2009. p. 59.

${ }^{12}$ WEDY, Gabriel. O Princípio Constitucional da Precaução, 2009, p. 69.

${ }^{13}$ MACHADO, Paulo Affonso Leme. Direito Ambiental Brasileiro, 2013, p. 1110.
}

Revista de Direito Brasileira | São Paulo, SP | v. 16 | n. 7 | p. 151 - 168 | Jan./Abr. 2017 
após dia mais inapreensível pela ciência e também pelos diversos processos jurisdicionais que têm por fim a tutela dos bens naturais. ${ }^{14} \mathrm{Em}$ sua obra sobre o risco ecológico abusivo, Silveira afirma que a construção do risco é um tema não somente científico, mas ético e político, pois a criação das condições que geram fatos negativos de maior ou menor dimensão resulta de escolhas técnicas e valorativas, conscientes ou inconscientes, de uma instituição, comunidade ou de um povo. $^{15}$

A partir dessas concepções, surge a importância da ideia de gestão de riscos, pois gestão envolve a construção de um diálogo eficaz entre quem tem conhecimento científico (as instituições, o Estado...), e quem efetivamente vive e sofre as consequências no ambiente que está vulnerável. É a própria ação humana que incide na compreensão dos riscos, assim como as decisões referentes a esses riscos pressupõem a valoração da ação humana, uma construção realizada por peritos e leigos, cada um em sua seara, e a partir de uma perspectiva democrática. ${ }^{16}$

Naturalmente, é necessário questionar como viabilizar uma avaliação do risco que possa efetivamente concluir se há ou não possibilidade de impacto de um perigo de dano ao meio ambiente e à saúde humana. Para Solange Teles da Silva, a estruturação da análise de risco deverá incluir três elementos: avaliação de riscos, gestão de riscos e comunicação de riscos:

Dentre as técnicas e dispositivos de avaliação, é possível citar: a) a definição de padrões de precaução, quer dizer, a pesquisa dos riscos das atividades que potencialmente impliquem riscos e adoção de parâmetros e procedimentos diante desses riscos; b) a adoção de uma atitude ativa em face dos riscos: a necessidade de desenvolvimento de pesquisa científica e técnica aplicada, o que implica a previsão orçamentária de verbas públicas para as instituições de ensino e pesquisa e a ampliação da capacidade de pesquisa do país; c) o desenvolvimento de perícias em matéria de riscos, passagem obrigatória para decisões públicas, sobretudo em matéria ambiental, onde existem inúmeras variáveis interativas; d) o incremento de técnicas de controle, vigilância e "traçabilidade", visto que a própria sociedade se torna um grande laboratório. ${ }^{17}$

É plausível, assim, esperar que haja uma construção eficiente de políticas de gestão de riscos que envolvam a estrutura das interações humanas e ecológicas, pela busca constante de novas tecnologias e o desenvolvimento econômico que não sejam capazes de consumir em demasiado os recursos ambientais. Uma gestão de riscos deve levar em conta o meio em que serão inseridas as políticas de proteção, pois essa é uma interação cultural, social, ambiental e ética. Essa gestão de riscos pressupõe que sejam adotadas as avaliações técnicas de riscos, como sugerido por Teles da Silva, bem como a posterior comunicação de riscos, envolvendo a sociedade sobre a qual recaem os riscos, no acesso às informações pertinentes e na oportunidade de tomar decisões a respeito dos fatos e dos empreendimentos.

Assumindo-se deliberadamente o risco, este pode tornar-se um evento de consequências irreversíveis para a vida humana e para a natureza. Evidentemente, não é adequado e viável que se espere a ocorrência de danos para então agir de forma incisiva no problema. Por isso, é necessário exigir-se uma avaliação prévia de impacto ambiental, como tem feito o Superior Tribunal de Justiça nas decisões a seguir analisadas.

${ }^{14}$ SILVEIRA, Clóvis Eduardo Malinverni da. Risco Ecológico Abusivo: a tutela do patrimônio ambiental nos Processos Coletivos em face do risco socialmente intolerável. Caxias do Sul: EDUCS, 2014, p. 318.

${ }^{15}$ SILVEIRA, Clóvis Eduardo Malinverni da. Risco Ecológico Abusivo, 2014, p. 328.

${ }_{17}^{16}$ SILVEIRA, Clóvis Eduardo Malinverni da. Risco Ecológico Abusivo, 2014, p. 336.

${ }^{17}$ SILVA, Solange Teles da. Princípio da Precaução: uma nova postura face aos riscos e as incertezas científicas. In: PLATIAU, Ana Flávia Barros; VARELlA, Marcelo Dias (Org.). Princípio da Precaução. Editora Del Rey e Escola Superior do Ministério Público da União. Disponível em: <http://www.marcelodvarella.org/meioambienteriscos.html>. Acesso em: 05 de maio de 2015.

Revista de Direito Brasileira | São Paulo, SP | v. 16 | n. 7 | p. 151 - 168 | Jan./Abr. 2017 


\section{A POSIÇÃO DO SUPERIOR TRIBUNAL DE JUSTIÇA A RESPEITO DA NECESSIDADE DE AVALIAÇÃO PRÉVIA DE IMPACTO AMBIENTAL FRENTE AO PRINCÍPIO DA PRECAUÇÃO}

O Superior Tribunal de Justiça tem se destacado nas decisões que envolvem o Direito Ambiental. Por ser um tribunal de alçada superior, suas decisões são tidas como referenciais nas justiças ordinárias, na doutrina e na construção de conceitos e normas. Buscando uma aplicação mais equânime e justa, o STJ tem se utilizado de princípios para integrar normas a casos concretos, especialmente no Direito Ambiental.

$\mathrm{Na}$ análise realizada neste capítulo será verificada a aplicação do princípio da precaução pelas turmas e pela Corte Especial do referido Tribunal, especificamente quando esse princípio é utilizado como fundamento para exigir a avaliação prévia de impacto ambiental. Para verificar a posição do STJ, detalha-se inicialmente a metodologia utilizada (3.1), passando, em seguida, para a análise das decisões (3.2).

\subsection{Metodologia}

Este item se dedica a apresentar as decisões e as respectivas análises de como, em quais situações e sob quais fundamentos o princípio da precaução vem sendo aplicado pelo Superior Tribunal de Justiça como base para a exigência da avaliação prévia de impacto ambiental. A partir de uma síntese dos fatos de cada decisão, é proposta uma análise realizada com enfoque específico no uso do princípio pelo STJ, não objetivando o mérito de outros possíveis temas dentro das decisões.

O instrumento utilizado para esta pesquisa foi a ferramenta "Pesquisa de Jurisprudência" disponibilizada no sítio de internet do STJ (http://www.stj.jus.br/SCON/), no dia 04 de setembro de 2016, tendo utilizado como termo de referência no campo "Pesquisa Livre" as palavras [princípio adj da adj precaução], tendo sido encontrados um total de 36 acórdãos. Nos critérios de pesquisa não foi delimitada uma data inicial, mas foi definida como data final 31/12/2015, chegando a um período de mais dez anos de aplicação do princípio, visto que a primeira decisão encontrada é de 01/09/2004.

Dessas 36 decisões, duas ${ }^{18}$ são de Direito Penal, proferidas pela Sexta Turma. Por não estarem relacionadas ao tema deste trabalho, as duas decisões de Direito Penal não são analisadas. Também foi encontrado o Recurso em Mandado de Segurança $\mathrm{n}^{\mathbf{0}} 44.246-\mathrm{RJ}{ }^{19}$, de relatoria do Ministro Og Fernandes, que trata de recurso de servidor público, diante de sua demissão após um processo administrativo disciplinar e não diz respeito ao princípio da precaução com o conteúdo de que trata o presente artigo.

Das 33 decisões restantes, nove ${ }^{20}$ não tratam efetivamente do princípio da precaução dentro dos votos, fazendo, por vezes, menção à precaução dentro de alguns conceitos

\footnotetext{
${ }^{18}$ BRASIL. Superior Tribunal de Justiça. AgRg no Resp no 998993/RS, Relator: Min. PAULO GALLOTTI, Sexta Turma, julgado em 05/03/2009, DJ-e 08/06/2009.

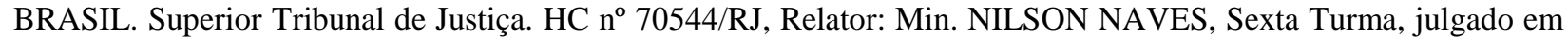
25/11/2008, DJ-e 03/08/2009.

${ }^{19}$ BRASIL. Superior Tribunal de Justiça. Recurso em MS no 44.246/RJ. Relator: Min. OG FERNANDES, Segunda Turma, julgado em 20/08/2015, DJ-e 04/09/2015.

${ }^{20}$ BRASIL. Superior Tribunal de Justiça. Resp no 745.363/ PR, Relator: Min. LUIZ FUX, Primeira Turma, julgado em 20/09/2007, DJ-e 18/10/2007.

BRASIL. Superior Tribunal de Justiça. Resp nº 975.397/RS, Relatora: Min. DENISE ARRUDA, Primeira Turma, julgado em 10/11/2009, DJ-e 01/12/2009.

BRASIL. Superior Tribunal de Justiça. Resp no 965.078/SP, Relator: Min. Herman Benjamin, Segunda Turma, julgado em 20/08/2009, DJ-e 27/04/2011.
}

Revista de Direito Brasileira | São Paulo, SP | v. 16 | n. 7 | p. 151 - 168 | Jan./Abr. 2017 
doutrinários, ou em algumas ementas citadas nas decisões, ou ainda em trechos das decisões de primeira e segunda instância, mas sem aprofundar sua abordagem.

Assim, restaram 24 decisões diretamente relacionadas à aplicação do princípio da precaução e com seu efetivo enfrentamento. Este artigo se restringe à análise das 8 decisões que versam sobre a avaliação prévia de impacto ambiental, deixando as demais para outros textos.

A metodologia e as técnicas de pesquisa tiveram inspiração no livro de Salo de Carvalho (Como não se faz um trabalho de conclusão) ${ }^{21}$, e na tese de doutorado de Fausto Santos de Moraes (Hermenêutica e Pretensão de Correção: Uma revisão crítica da aplicação do princípio da proporcionalidade pelo Supremo Tribunal Federal ${ }^{22}$ sob orientação do professor Dr. Lênio Luiz Streck.

Passa-se, no próximo tópico, à análise das 8 decisões encontradas sobre o tema proposto neste artigo.

\subsection{Análise das Decisões}

Neste tópico são analisadas as decisões que utilizam o princípio da precaução como fundamento para exigir a avaliação prévia de impacto ambiental. As informações sobre as partes, o objeto da ação e o histórico processual foram buscadas no interior dos acórdãos analisados. Para facilitar a análise, primeiro realiza-se a descrição de cada decisão para, depois, realizar-se um estudo com a introdução da doutrina. A avaliação prévia de impacto ambiental é imprescindível, como visto a seguir, para que as dúvidas quanto à danosidade de empreendimentos ou atividades sejam sanadas a ponto de não permitir que resultados negativos para o meio ambiente e a saúde de todos se sobreponham posteriormente.

1) No Agravo Regimental na Suspensão de Tutela Antecipada $n^{\circ} 88 / \mathrm{DF}^{23}$ de relatoria do Ministro Edson Vidigal, o Ministério Público do Distrito Federal (DF) propôs ação civil pública contra o Distrito Federal e a Companhia Urbanizadora da Nova Capital do Brasil, exigindo a paralisação da duplicação da L4 Norte e da implantação da via de ligação da Estrada Parque Dom Bosco e Estrada Parque Contorno, pois a realização das obras continha vícios. A tutela antecipada foi deferida pelo juízo de primeiro grau, posteriormente foi revogada, e adveio agravo que restabeleceu a tutela, paralisando novamente as obras, alegando inexistência de estudo de impacto ambiental e análise técnica pelo Departamento Estadual de Trânsito.

O Distrito Federal recorreu, alegando: a) que a obra seria apenas uma via de ligação urbana, o que exigiu um Relatório de Controle Ambiental (RCA) e um Plano de Recuperação de

BRASIL. Superior Tribunal de Justiça. Resp n ${ }^{\circ}$ 1.090.968/SP, Relator: Min. LUIZ FUX, Primeira Turma, julgado em 15/06/2010, DJ-e 03/08/2010.

BRASIL. Superior Tribunal de Justiça. Resp n 1.163.939/RS, Relator: Min. MAURO CAMPBELL MARQUES, julgado em 14/12/2010, DJ-e 08/02/2011.

BRASIL. Superior Tribunal de Justiça. AgRg no Agravo em Resp n 206.748/SP, Relator: Min. RICARDO VILLAS BÔAS CUEVAS, Terceira Turma, jugado em 28/05/2013, DJ-e 10/06/2013.

BRASIL. Superior Tribunal de Justiça. AgRg no Resp no 1.322.363/RS, Relator: Min. CASTRO MEIRA, Segunda Turma, julgado em 20/08/2013, DJ-e 30/08/2013.

BRASIL. Superior Tribunal de Justiça. AgRg no Resp no 431.420/MG, Relator: Min. HUMBERTO MARITNS, Segunda Turma, julgado em 06/02/2014, DJ-e 17/02/2014.

${ }^{20}$ BRASIL. Superior Tribunal de Justiça. AgRg na Suspensão de Liminar e de Sentença no 1.429/GO, Relator: Min. ARI PERGENDLER, Corte Especial, julgado em 05/12/2011, DJ-e 29/02/2012.

${ }^{21}$ CARVALHO, Salo de. Como (não) se faz um trabalho de conclusão: provocações úteis para orientadores e estudantes de direito. 2. ed. São Paulo: Saraiva, 2013.

${ }^{22}$ MORAES, Fausto Santos de. Hermenêutica e Pretensão de Correção: Uma revisão crítica da aplicação do princípio da proporcionalidade pelo Supremo Tribunal Federal. 2013. 346f. Tese de doutoramento em Direito. São Leopoldo: UNISINOS, 2013.

${ }^{23}$ BRASIL. Superior Tribunal de Justiça. AgRg na Suspensão de tutela antecipada no 88/DF, relator: Min. EDSON VIDIGAL, Corte Especial, julgado em 01/09/2004, DJ-e 09/05/2005.

Revista de Direito Brasileira | São Paulo, SP | v. 16 | n. 7 | p. 151 - 168 | Jan./Abr. 2017 
Área Degradada (que foram realizados); b) que as obras estavam 93\% concluídas; c) que o empreendimento representa elevada importância social e econômica; d) que haveria risco de lesão à saúde pública, pois existiria presença de material das obras no ar, além dos riscos de acidente; e e) possibilidade de lesão econômica pelos investimentos já realizados.

O Distrito Federal teve seu pedido atendido e adveio agravo do Ministério Público que, em seus argumentos, utilizou o princípio da precaução, já que existiam provas: a) da "ausência do estudo de impacto ambiental para a consecução da obra"; e b) da "existência de várias irregularidades no processo de licenciamento ambiental para a construção da malha viária" que poderiam causar " uma série de danos irreversíveis ao local". Diante disso, requereu a aplicação do "princípio da precaução, o qual recomenda a paralisação imediata das obras para que a situação possa ser rigorosamente observada enquanto perdurar o processamento da ação civil pública". O pedido de reconsideração do agravo foi negado por unanimidade, mantendo-se a execução das obras, tendo por um dos fundamentos do relator o fato de não ser caso de aplicação do princípio da precaução. Cabe ressaltar a observação do voto do Ministro Francisco Peçanha Martins:

Fico muito tranquilo por ter o nosso Presidente sobrevoado a área para constatar, pelo menos in loco, que essa agressão não se fará tão intensa. Não sou daqueles que são radicais na preservação do meio ambiente. Penso que o meio ambiente deve servir ao homem, e no caso, há previsão - com base em estudos feitos - de que essa via de acesso tenha existência de modo a servir toda a população, por isso não vejo como impedir sua construção. ${ }^{24}$

Assim, parece ter prevalecido o interesse econômico na continuidade da obra, em detrimento da proteção ambiental que poderia haver em caso de maior avaliação das consequências da obra.

2) A seguinte decisão é o Agravo Regimental na Suspensão de Liminar e de Sentença no $1.323 / \mathrm{CE}^{25}$ de relatoria do Ministro Ari Pargendler. Esse Agravo foi interposto contra o deferimento do pedido do Ministério Público e da Superintendência Estadual do Meio Ambiente em ação civil pública para paralisar a construção de um condomínio residencial dos agravantes Helder Ferreira Pereira Forte e Cameron Construtora Ltda. O empreendimento está situado em Área de Preservação Permanente e as licenças para a construção foram flagrantemente obtidas em afronta à legislação ambiental e sem os estudos exigidos para a área. A licença prévia e a licença de instalação foram concedidas em apenas quatro dias, em 2006. No pedido de renovação da licença de instalação, em 2008, foram constatas pela Superintendência Estadual do Meio Ambiente irregularidades que resultaram em auto de infração, indeferimento do pedido de renovação de licença e embargo administrativo da obra. Os pereceres técnicos realizados concluíram pelo embargo definitivo da obra. Quatro estudos atestaram que a obra estava sendo realizada em APP, o que por si só, já impediria a realização da mesma. Por fim, foi negado provimento ao agravo, por unanimidade com base também no princípio da precaução já que, em uma situação como essa, é recomendada a paralisação das obras com vistas a proteger o meio ambiente, porque os danos por elas causados podem ser irreversíveis acaso a demanda seja ao final julgada procedente e as obras já estiverem concluídas e os imóveis vendidos. Assim, prevaleceu o interesse público de preservação ambiental sobre interesses privados.

\footnotetext{
${ }^{24}$ Trecho do voto do Ministro Francisco Peçanha Martins no Agravo Regimental na Suspensão de Tutela Antecipada $n^{\circ}$ 88/DF.

${ }^{25}$ BRASIL. Superior Tribunal de Justiça. AgRg na Suspensão de Liminar e de Sentença $n^{\circ}$ 1.323/CE, relator: Min. ARI PARGLENDER, Corte Especial, julgado em 16/03/2011, DJ-e 02/08/2011.
} 
3) O próximo caso a ser analisado é a proposição do agravo Regimental na Suspensão de Liminar e de Sentença $\mathrm{n}^{\mathrm{o}}$ 1.279/PR ${ }^{26}$ de relatoria do Ministro Ari Pargendler, interposto contra a medida de suspensão de atividades de instalação de um aterro sanitário que teve seu licenciamento atacado por meio de ação popular. Inicialmente deferida, a medida liminar de suspensão da instalação teve os efeitos suspensos pelo relator, no âmbito de agravo de instrumento. Posteriormente, o IBAMA embargou a obra. A empreendedora Ponta Grossa Ambiental Ltda. ajuizou ação ordinária contra o IBAMA, na qual a antecipação de tutela foi deferida. Sobreveio suspensão de liminar e sentença favorável ao IBAMA que foi objeto de recurso pela empreendedora. $\mathrm{O}$ agravo foi improvido por unanimidade, por entender o relator que, naquela situação, deve prevalecer o princípio da precaução, mantendo-se a paralisação da instalação do aterro.

Nesse processo, o Instituto Chico Mendes de Preservação da Biodiversidade (ICMBio) alegou erros grosseiros no mérito do EIA, afirmando que havia a probabilidade de o chorume do aterro atingir a bacia de manancial que abastece o Município de Ponta Grossa. A decisão inicial ressaltou a precaução, fundamentando que na tutela do meio ambiente não se pode aguardar a ocorrência de danos porque os mecanismos da tutela de reparação não são aptos a possibilitar a recuperação do meio ambiente pós-degradação. Foi dito que o EIA manipulou claramente a escolha do local favorecendo a empresa, em detrimento de outros locais mais adequados para a sua instalação.

4) No Agravo Regimental na Suspensão de Liminar e de Sentença $n^{\circ} 1.302 / \mathrm{PE}^{27}$ de relatoria do Ministro Ari Pargendler, trata-se de processo em que a justiça federal deferiu o pedido de liminar para determinar a suspensão de certame licitatório realizado pelo ICMBio (agravado), que tinha por objetivo conceder a empresas privadas a cobrança de ingresso e exploração comercial do Parque Nacional Marinho Fernando de Noronha. A liminar foi concedida e um de seus fundamentos foi a ausência de EIA diante dos impactos que poderiam advir da exploração econômica do local.

O ICMBio interpôs Agravo de Instrumento, pedindo a suspensão da liminar, alegando ilegitimidade da decisão por não ser necessário o EIA naquele caso, pois o intuito do processo era delimitar e proteger as áreas de passeio já existentes pelo parque, garantindo as condições ideais para o pleno exercício das atividades de turismo ecológico. O Agravo de Instrumento foi deferido, tendo como um dos fundamentos o princípio da precaução, adotando a versão do ICMBio como a mais razoável para a sua aplicação, tendo em vista que o processo licitatório está focado na conservação do parque, já que a regulamentação e recuperação da área de caminhadas visa justamente controlar e dar o destino adequado ao lixo gerado na visitação, cobrança de ingressos, reforma dos atuais postos de informação, pontos de controle e apoio ao visitante, entre outros. A visitação desregrada poderia degradar ainda mais o meio ambiente. Sobre essa decisão incidiu o referido agravo que foi negado por unanimidade, sob os fundamentos da decisão agravada.

5) O Recurso Especial $\mathrm{n}^{\mathrm{o}} 1.279 .607 / \mathrm{PR}^{28}$ de relatoria do Ministro Mauro Campbell Marques, interposto pelo Ministério Público Federal contra acórdão que entendeu que descabia exigência de EIA/RIMA para um licenciamento ambiental quando o IBAMA entendia ser necessário apenas o Relatório de Controle Ambiental (RCA). O MP, entre suas razões, alegou ter havido inobservância do princípio da precaução. No voto, o relator entende que não apenas o EIA faz cumprir o papel do princípio, mas também o RCA. Ainda, que cabia ao IBAMA analisar a

\footnotetext{
${ }^{26}$ BRASIL. Superior Tribunal de Justiça. AgRg na Suspensão de Liminar e de Sentença no $1.279 / \mathrm{PR}$, relator: Min. ARI PARGLENDER, Corte Especial, julgado em 16/03/2011.

${ }^{27}$ BRASIL. Superior Tribunal de Justiça. AgRg na Suspensão de Liminar e de Sentença no 1.302/PE, Relator: Min. ARI PARGLENDER, Corte Especial, julgado em 15/12/2010, DJ-e 11/03/2011.

${ }^{28}$ BRASIL. Superior Tribunal de Justiça. Resp no 1.279.607/PR, Relator: Min. MAURO CAMPBELL MARQUES, Segunda Turma, julgado em 06/12/2011, DJ-e 13/12/2011.
}

Revista de Direito Brasileira | São Paulo, SP | v. 16 | n. 7 | p. 151 - 168 | Jan./Abr. 2017 
necessidade ou não de EIA, mas também que sua conclusão não é absoluta, mas sindicável pela via judicial. Por unanimidade, o recurso foi parcialmente provido, no sentido de que o Tribunal avaliasse se havia ou não necessidade de EIA/RIMA, como sugere o Ministério Público, afastando o fundamento de que as conclusões do IBAMA não são questionáveis na via judicial.

6) Já o Recurso Especial n ${ }^{\circ} 1.285 .463 / \mathrm{SP}^{29}$ de relatoria do Ministro Humberto Martins trata de recurso interposto pelo Ministério Público de São Paulo em sede de ação civil pública, contra decisão que declarou que, inexistindo dado científico concreto, o Judiciário não poderia paralisar a atividade canavieira do Estado. Essa atividade seria responsável por, pelo menos, quinze milhões de empregos diretos e indiretos, permitindo a queima de palha de cana-de-açúcar sem a necessidade de adoção de medidas menos poluentes. ${ }^{30}$ Contra a alegação de violação da Súmula $7 / \mathrm{STJ}^{31}$,o relator fundamentou que não é preciso revisar provas e dados fáticos constantes no acórdão para sentenciar que a proteção do meio ambiente é incondicionada a certezas científicas. Em seu voto, o Ministro ainda fez constar:

A ausência de certeza científica, longe de justificar uma ação possivelmente degradante do meio ambiente, deveria incitar o julgador a mais prudência. Tudo isso, obviamente, deve harmonizar-se com o desenvolvimento sócioeconômico, não podendo obstá-lo de modo irremediável. Deve-se, aqui, buscar uma solução para o que parece ser uma tensão entre postulados constitucionais. Ensina-nos a moderna teoria constitucional que a situação de tensão de princípios deve ser resolvida pela ponderação, fundamentada e racional, entre os valores conflitantes. [...] Busca-se com isso compatibilizar dois valores protegidos [...], o meio ambiente e a cultura ou o modo de fazer, este quando necessário à sobrevivência dos pequenos produtores que retiram seu sustento da atividade agrícola e que não dispõem de outros métodos para o exercício desta, que não o uso do fogo. ${ }^{32}$

Como no caso se tratava de atividade agroindustrial, em que o poder econômico permite investimentos em novas tecnologias, não há que se falar em exceção de autorização prevista no Código Florestal. Assim, mesmo que a Administração Pública possa autorizar queimas de palha, estas devem ser específicas, precedidas de EIA e licenciamento, com a implementação de medidas que permitam amenizar danos e recuperar o ambiente degradado. A turma, por unanimidade, deu provimento ao recurso contra a Fazenda do Estado de São Paulo e a Companhia de Tecnologia e Saneamento Ambiental (CETESB), proibindo a prática de queima de palha de cana-de-açúcar.

\footnotetext{
${ }^{29}$ BRASIL. Superior Tribunal de Justiça. Resp $n^{\circ}$ 1.285.463/SP, Relator: Min. HUMBERTO MARTINS, Segunda Turma, julgado em 28/02/2012, DJ-e 06/03/2012.

${ }^{30}$ Estudos apontam o crescimento do uso de máquinas sofisticadas na colheita de cana-de-açúcar que não requeiram a queima posterior da palha. Apesar de ser um grande investimento, esse investimento tem se mostrado mais vantajoso economicamente do que a colheita manual que resulta na queima da palha. "A prática da queima da palha da cana, adotada corriqueiramente no Estado de São Paulo, gera notáveis impactos ambientais, decorrentes da emissão de gases poluentes nocivos à qualidade de vida e à saúde da população que reside nas áreas de cultivo de cana ou no seu entorno. Todavia, diante da relevante importância da atividade sucroalcooleira para a economia e geração de empregos, renda, divisas e tributos, aliadas às medidas de responsabilidade diante das mudanças climáticas globais, com o fim de evitar o agravamento das condições ambientais desfavoráveis à qualidade de vida, foi assinado um protocolo de cooperação entre o governo e o setor sucroalcooleiro, visando a consolidar o desenvolvimento sustentável da indústria da cana-de-açúcar no Estado de São Paulo.” (NOVAES, Maikon R. de; RUDORFF, Bernardo F. T; ALMEIDA, Cláudia M. de; AGUIAR, Daniel A. de. Análise espacial da redução da queima na colheita da cana-de-açúcar: perspectivas futuras ao cumprimento do protocolo agroambiental. Eng. Agríc. 2011, vol.31, n.3, p. 572-583).

${ }^{31}$ BRASIL. Súmula 7/STJ: A pretensão de simples reexame de provas não enseja recurso especial. Disponível em: < http://www.stj.jus.br/docs_internet/VerbetesSTJ_asc.pdf >. Acesso em: 15 de maio de 2015.

${ }^{32}$ Trecho do voto do Ministro Humberto Martins na decisão do Recurso Especial no ${ }^{\circ}$.285.463/SP
}

Revista de Direito Brasileira | São Paulo, SP | v. 16 | n. 7 | p. 151 - 168 | Jan./Abr. 2017 
7) No Agravo Regimental na Suspensão de Liminar e de Sentença $n^{\circ} 1.524 / \mathrm{MA}^{33}$, de relatoria do Ministro Ari Pargendler, discute-se acerca da legalidade do licenciamento ambiental da ampliação da Avenida Litorânea na cidade de São Luís, no Maranhão, simultaneamente na Justiça Comum e na Justiça Federal, ambas em ação civil pública. Na Justiça Comum, foi determinada a suspensão do procedimento em decisão que foi levada a recurso ao STJ. Na Justiça Federal, embora inicialmente suspenso o procedimento, o Tribunal Regional Federal da $1^{\mathrm{a}}$ Região determinou o seu regular procedimento. O Município, por sua vez, alegou impedimento do desenvolvimento sustentável da cidade, deflagrando dano à ordem administrativa. Por unanimidade, na decisão ora analisada o STJ negou provimento ao agravo interposto pelo Município de São Luís contra o Ministério Público do Maranhão, suspendendo o procedimento de licenciamento ambiental até que fossem sanadas as dúvidas acerca do possível impacto da obra, resguardando o interesse público de proteção ambiental. O processo apontou indícios de irregularidades no procedimento de licenciamento ambiental, sobretudo no EIA/RIMA, tornando necessária a suspensão dos atos posteriores.

8) Por fim, analisa-se o Agravo Regimental na Suspensão de Liminar e de Sentença ${ }^{\circ}$ 1.564/ $\mathrm{MA}^{34}$, de relatoria do Ministro Ari Pargendler. Inicialmente, o Ministério Público Federal ajuizou ação civil pública contra o Estado do Maranhão e a Suzano Papel e Celulose S/A que, em maio de 2009, após a obtenção de licença de instalação e licença de operação (que ocorreram no mesmo dia), iniciou os trabalhos de desmatamento da vegetação nativa nas terras arrendadas, dando prosseguimento aos seus planos de implantação do Projeto Florestal e Produção de Carvão. Obteve, ainda, autorização para a supressão de vegetação, possibilitando o desmatamento de 5.715,26 hectares dentro de um imóvel de 7.591,12 hectares. Essas licenças foram concedidas por órgão estadual. Porém, a competência sria do IBAMA, conforme Resolução do Conselho Nacional do Meio Ambiente (CONAMA) 378/06 ${ }^{35}$, por se tratar de supressão de florestas em área maior que mil hectares, em imóveis rurais localizados fora da Amazônia Legal. Em agravo de instrumento, o pedido de antecipação de tutela do Ministério Público foi deferido para suspender a eficácia dos atos administrativos produzidos pelo Estado do Maranhão relativos ao licenciamento ambiental. Nesse agravo, cabe observar o voto do relator:

Em matéria de meio ambiente vigora o princípio da precaução. Esse princípio deve ser observado pela Administração Pública, e também pelos empreendedores. A segurança dos investimentos constitui, também e principalmente, responsabilidade de quem os faz. À luz desse pressuposto, surpreende na espécie a circunstância de que empreendimento de tamanho vulto tenha sido iniciado e continuado, sem que seus responsáveis tenham se munido da cautela de consultar o órgão federal incumbido de preservar o meio ambiente a respeito de sua viabilidade. ${ }^{36}$

A decisão manteve a impugnação das licenças, por unanimidade, negando provimento ao agravo.

\footnotetext{
${ }^{33}$ BRASIL. Superior Tribunal de Justiça. AgRg na Suspensão de Liminar e de Sentença no 1.524/MA, Relator: Min. ARI PARGENDLER, Corte Especial, julgado em 02/05/2012, DJ-e 18/05/2012.

${ }^{34}$ BRASIL. Superior Tribunal de Justiça. AgRg na Suspensão de Liminar e de Sentença n 1.564/MA, Relator: Min. ARI PARGENDLER, Corte Especial, julgado em 16/05/2012, DJ-e 06/06/2012.

${ }^{35}$ Art. $1^{\circ}$ Para fins do disposto no inciso III, $\S 1^{\circ}$, art. 19 da Lei no 4.771 , de 15 de setembro de 1965 , com redação dada pelo art. 83 da Lei $n^{\circ} 11.284$, de 2 de março de 2006, compete ao Instituto Brasileiro do Meio Ambiente e dos Recursos Naturais Renováveis-IBAMA a aprovação dos seguintes empreendimentos: III - supressão de florestas e outras formas de vegetação nativa em área maior que: [...] b) mil hectares em imóveis rurais localizados nas demais regiões do país.

${ }^{36}$ Trecho do voto do Ministro Ari Pargendler na decisão acerca do Agravo Regimental na Suspensão de Liminar e de Sentença $\mathrm{n}^{\circ}$ 1.564/MA.
}

Revista de Direito Brasileira | São Paulo, SP | v. 16 | n. 7 | p. 151 - 168 | Jan./Abr. 2017 
As decisões que integram este artigo também não aprofundam o desenvolvimento do conceito de princípio da precaução e em alguns momentos aplicam de forma equivocada o princípio da precaução onde deveriam, na verdade, aplicar o princípio da prevenção (AgRg $\mathrm{n}^{\circ}$ 1.323/CE, AgRg n ${ }^{\circ} 1.279 / \mathrm{PR}$, Resp. $\mathrm{n}^{\circ}$ 1.285.463/SP). Como se sabe, quando se reconhece a existência de riscos, os tipos de dano e suas consequências, aplicam-se medidas preventivas e não as precaucionais.

As decisões analisadas se destacam por terem em seu conteúdo dois pontos cruciais na proteção ambiental: o licenciamento regular de empreendimentos e as avaliações prévias de impacto ambiental. Essas avaliações se materializam especialmente através do Estudo de Impacto Ambiental e do relatório produzido através dele, o RIMA, que permite que os resultados obtidos sejam sintetizados, servindo de esclarecimento em audiências públicas. Quando realizado de forma correta, o EIA se torna um dos mais eficazes instrumentos de atuação administrativa na proteção ambiental.

Antes de falar propriamente do EIA, cabe destacar o conceito de impacto ambiental que está definido na Resolução CONAMA nº 001/86:

Artigo $1^{\circ}$ - Para efeito desta Resolução, considera-se impacto ambiental qualquer alteração das propriedades físicas, químicas e biológicas do meio ambiente, causada por qualquer forma de matéria ou energia resultante das atividades humanas que, direta ou indiretamente, afetam:

I - a saúde, a segurança e o bem-estar da população;

II - as atividades sociais e econômicas;

III - a biota;

IV - as condições estéticas e sanitárias do meio ambiente;

$\mathrm{V}$ - a qualidade dos recursos ambientais. ${ }^{37}$

Essa resolução também prevê os casos expressos em que o EIA/RIMA deve ser realizado, não sendo o rol taxativo. Na legislação brasileira, o EIA é um instrumento previsto constitucionalmente, cabendo ao Poder Público "exigir, na forma da lei, para instalação de obra ou atividade potencialmente causadora de significativa degradação do meio ambiente, estudo prévio de impacto ambiental, a que se dará publicidade" (Art. 225, § $1^{\circ}, \mathrm{IV}$ ).

Além disso, normas infraconstitucionais e resoluções também regulamentam as avaliações prévias de impacto ambiental, incluindo o EIA e o licenciamento ambiental, como a Lei $\mathrm{n}^{\circ}$ 6.938/81, que prevê, em seu art. $9^{\circ}$, como instrumentos da Política Nacional do Meio Ambiente, "a avaliação de impactos ambientais" (III) e o "o licenciamento e a revisão de atividades efetiva ou potencialmente poluidoras" (IV). Essa exigência é detalhada pela a resolução do CONAMA nº 237/97:

Art. $3^{\circ}$ - A licença ambiental para empreendimentos e atividades consideradas efetiva ou potencialmente causadoras de significativa degradação do meio dependerá de prévio estudo de impacto ambiental e respectivo relatório de impacto sobre o meio ambiente (EIA/RIMA), ao qual dar-se-á publicidade, garantida a realização de audiências públicas, quando couber, de acordo com a regulamentação. ${ }^{38}$

O EIA, em princípio, é utilizado como uma ferramenta de prevenção, tendo em vista que deve ser realizado antes da instalação de atividades que tem seu potencial causador de estragos

${ }^{37}$ Resolução CONAMA no 001/86. Disponível em: <http://www.mma.gov.br/port/conama/res/res86/res0186.html〉. Acesso em: 20 de maio de 2015.

38 Resolução $\quad$ CONAMA 237/97. Disponível em: <http://www.mma.gov.br/port/conama/res/res97/res23797.html>. Acesso em: 20 de maio de 2015. 
conhecido, apontando medidas mitigadoras de possíveis danos. Porém, o EIA possui potencial para tornar-se uma ferramenta de precaução, já que tem por objetivo a elaboração de estudos e pareceres que podem fornecer um padrão de segurança a ser seguido, um limite de risco, delimitando também as medidas de proteção cabíveis.

As decisões analisadas demonstram que essa possibilidade está sendo ampliada pelo STJ, pois esse Tribunal Superior vem qualificando o EIA/RIMA como instrumento de cumprimento do princípio da precaução. As falhas nos estudos, as inconsistências apontadas e as irregularidades expostas nos processos, em grande parte das lides resultaram na aplicação do princípio da precaução, que acabaram em suspensão de obras e suspensão de licenças administrativas concedidas indiscriminadamente.

Milaré $^{39}$, ao falar sobre o EIA, avalia-o como um notável instrumento do desenvolvimento econômico-social:

Como modalidade de Avaliação de Impacto Ambiental (AIA), o Estudo de Impacto Ambiental (EIA) é hoje considerado um dos mais notáveis instrumentos de compatibilização do desenvolvimento econômico-social com a preservação da qualidade do meio ambiente, já que deve ser elaborado antes da instalação de obra ou de atividade $[\ldots]$

O autor ainda exalta o quanto esse estudo significou para a proteção ambiental, considerando-o um marco de evolução, levando-se em conta que até a década de 1980 a insensibilidade do Poder Público não impedia obras gigantescas, seriamente comprometedoras do meio ambiente e que causavam grandes impactos locais e regionais. ${ }^{40}$

Porém, como ressaltado nas decisões, o EIA é falível, e isso merece uma grande atenção por parte do Poder Público e da própria sociedade. Justamente por ser um instrumento de maior valia, de elevada importância, por ser um instrumento técnico de esclarecimento e que atesta as condições de viabilidade e a segurança de uma obra e atividade é que cabem observações acerca de seus pontos frágeis.

Partindo da observação desses pontos e da necessidade de se corrigi-los, em 2004, foi elaborada uma análise qualitativa e multidisciplinar fundamentada essencialmente na experiência específica de analistas periciais e assessores do Ministério Público Federal, que apontou detalhadamente essas falhas nas diversas etapas do estudo e do relatório, entendendo como necessários para a melhoria da qualidade do EIA os seguintes pontos:

1. Consideração das variáveis ambientais de empreendimentos desde a fase de planejamento das políticas públicas;

2. Garantia de prazos suficientes para a elaboração dos Estudos;

3. Maior integração e diversidade disciplinar das equipes que executamos diferentes estudos que compõem um mesmo EIA, promovendo a interdisciplinaridade;

4. Maior investimento no conhecimento das realidades sociais locais, mediante a investigação sobre as visões de mundo, valores e princípios que as organizam, contribuindo para a busca do equilíbrio na divisão social das externalidades positivas e negativas, a efetiva escolha de alternativas e a tomada de decisão;

5. Criação de mecanismos que possibilitem maior cooperação e intercâmbio de informações entre diferentes órgãos governamentais, a partir da elaboração do Termo de Referência, de forma que inclua nos Estudos a consideração de questões diferentes daquelas afetas apenas ao órgão licenciador;

\footnotetext{
${ }^{39}$ MILARÉ, Édis. Direito do Ambiente, 2014, p. 757.

${ }^{40}$ MILARÉ, Édis. Direito do Ambiente, 2014, p. 757.
}

Revista de Direito Brasileira | São Paulo, SP | v. 16 | n. 7 | p. 151 - 168 | Jan./Abr. 2017 
6. Maior rigor na exigência de qualidade em todos os Estudos e maior investimento em multidisciplinaridade das equipes dos órgãos licenciadores, para que orientem em tempo a elaboração adequada, rejeitando aqueles que não resultem em AIA adequada;

7. Criação e/ou consolidação, por parte dos órgãos ambientais, de banco de dados dos Estudos, possibilitando o registro e o acesso aos conhecimentos produzidos, inclusive reduzindo prazos e custos para a elaboração de novos Estudos;

8. Consolidação de banco de dados das informações oriundas da implementação de medidas mitigadoras e de monitoramento, por parte dos órgãos ambientais; e

9. Estímulo e ampliação da participação social, desde a realização dos estudos, até a fase de avaliação, favorecendo o reconhecimento de direitos sociais, ambientais e culturais. ${ }^{41}$

No cenário atual, a importância da utilização de instrumentos técnicos e eficientes de proteção ambiental é indiscutível. Aproveitar um instrumento já existente demanda sua expansão e adequação, mas é certamente o caminho mais viável e mais curto para alcançar o sucesso com o desenvolvimento sustentável.

Também, é importante uma eficiente gestão de políticas públicas que incentivem o desenvolvimento sustentável, que enxerguem como investimento a implantação de novas tecnologias ambientais, a capacitação de órgãos de proteção do meio ambiente, a implantação de estudos ambientais em nível escolar, o incentivo de instalação de empreendimentos que tenham uma visão e uma missão efetivamente sustentável. E, sobretudo, que também atue de forma a fiscalizar e punir quem hoje ainda considere apenas o dinheiro e o lucro a qualquer custo em detrimento do bem ambiental, da vida e da qualidade de vida.

\section{CONCLUSÃO}

Nas decisões judiciais analisadas neste artigo, que envolviam avaliação prévia de impacto ambiental, o que se discutiu foram as irregularidades na formulação dos estudos e nos procedimentos de licenciamento e, até mesmo, a ausência de EIA quando de sua necessidade. O princípio da precaução, na maioria delas, é utilizado como fundamento para realização dos estudos e para a paralisação de obras em situações nas quais esses estudos são duvidosos.

Dessas decisões, algumas são casos de aplicação do princípio da prevenção por terem seus danos indiscutivelmente conhecidos (AgRg na Suspensão de Liminar e Sentença $n^{\circ}$ 1.323/CE, AgRg na Suspensão de Liminar e Sentença no 1.279/PR, Resp nº 1.285.463/SP). Das oito decisões analisadas, apenas uma ignorou a aplicação do princípio da precaução, mantendo a execução de obras de grande porte sem o EIA (AgRg na Suspensão de Tutela Antecipada $n^{\circ}$ 88/DF).

Conclui-se que o STJ, na grande maioria de seus julgados no recorte aqui realizado, vem qualificando o EIA/RIMA como instrumento de cumprimento do princípio da precaução, determinado, inclusive, sob fundamento de falhas, irregularidades ou ausência de EIA, a suspensão de obras e a suspensão de licenças administrativas concedidas indiscriminadamente.

Merece destaque, também, a relevante atuação do Ministério Público, seja no âmbito estadual, seja no federal, que intervém judicialmente em favor do meio ambiente. É importante que essa atuação continue avançando, aliada a diálogos com outros órgãos de defesa ambiental,

\footnotetext{
${ }^{41}$ Deficiências em estudos de impacto ambiental: síntese de uma experiência. Brasília: Ministério Público Federal, $4^{a}$ Câmara de Coordenação e Revisão: Escola Superior do Ministério Público da União, 2004, p. 43, 44. Disponível em: < http://escola.mpu.mp.br/linha-editorial/outras-publicacoes/impacto_ambiental3.pdf >. Acesso em 04/09/2016.

Revista de Direito Brasileira | São Paulo, SP | v. 16 | n. 7 | p. 151 - 168 | Jan./Abr. 2017
} 
para que seja possível chegar a respostas efetivas aos danos e para que não seja mais preciso buscar soluções após a concretização dos danos.

Outro ponto de destaque na aplicação do princípio da precaução é a legitimação do EIA/RIMA como instrumento apto a concretizar medidas precaucionais. Observando a necessidade de aprimoramento e as críticas construtivas vistas com relação ao EIA, esse tem se tornado um instrumento legal de grande relevância quando realizado de forma séria. Capaz de produzir parâmetros de segurança, padrões mínimos a serem observados, medidas reparadoras e ainda, de proporcionar o conhecimento e a transparência para legitimar qualquer investimento, aplacando os riscos.

Com isso, permite-se que a avaliação de riscos em processos decisórios seja pautada na prudência e tenha em conta não apenas o contexto imediato, mas de longo prazo. Essa avaliação de riscos tem a vantagem, ainda, de ser interdisciplinar e considerar os diversos aspectos de riscos, sejam eles econômicos, sociais, ambientais... No contexto brasileiro o EIA tem se mostrado um instrumento capaz de implementar uma abordagem precaucional ao caso concreto. 42

É possível observar que em pouco mais de dez anos de aplicação do princípio da precaução, ainda há muito a ser analisado. O princípio da precaução ainda gera divergências doutrinárias e jurisprudenciais. De qualquer forma, necessário investir em uma aplicação positiva do princípio da precaução, visando combater uma perspectiva anti-precaucional que vem sendo implementada através das políticas públicas ambientais no país. ${ }^{43}$

Caubet também se posiciona criticamente quanto a não precaução e a não prevenção com relação as decisões administrativas no âmbito do Direito Ambiental, por constatar que "nenhum projeto de empreendimento apresenta riscos" considerados "suficientemente elevados" para serem indeferidos e proibidos com base no princípio da precaução ou que o princípio da precaução "não possui carga normativa suficiente para ensejar efeitos jurídicos". ${ }^{44}$ Isso gera insegurança jurídica e operacional do princípio, levando à negligência com relação à sua importância.

A discussão acerca de um parâmetro para a aplicação mais incisiva do princípio da precaução é relevante e precisa acontecer o mais rápido possível. Não é possível que haja apenas uma ou algumas decisões que se valham desse importante princípio. Esse é um princípio que precisa ser adotado como norte estruturador de políticas públicas ambientais, na gestão e avaliação de riscos e na formulação de parâmetros de segurança. Enfim, para possibilitar a própria existência de vida em um contexto cada vez mais permeado por riscos indefinidos e pela incerteza científica diante de tantas mudanças naturais e de perspectivas pessimistas.

\section{REFERÊNCIAS}

ANTUNES, Paulo de Bessa. Direito Ambiental. 16. ed. São Paulo: Atlas, 2014.

BRASIL. Lei nº 6.938/1981. Lei da Política nacional do Meio Ambiente. Disponível em: < http://www.planalto.gov.br/ccivil_03/leis/16938.htm>. Acesso em: maio de 2015.

\footnotetext{
${ }^{42}$ SILVEIRA, Clóvis Eduardo Malinverni da.Políticas públicas e processos decisórios em matéria de biossegurança à luz do princípio de precaução. In: LEITE, José Rubens Morato; PERALTA, Carlos E. (Org.). Perspectivas $e$ desafios para a proteção da biodiversidade no Brasil e na Costa Rica. São Paulo: Instituto o Direito por um Planeta Verde, 2014, p. 355-357.

${ }^{43}$ SILVEIRA, Clóvis Eduardo Malinverni da. Políticas públicas e processos decisórios..., 2014, p. 361.

${ }^{44}$ CAUBET, Christian Guy. O conceito de sociedade de risco como autoabsolvição das sociedades industriais infensas à responsabilidade jurídica. Cadernos de Direito, Piracicaba, v. 13(24): 63-84, jan.-jun. 2013, p. 81.
}

Revista de Direito Brasileira | São Paulo, SP | v. 16 | n. 7 | p. 151 - 168 | Jan./Abr. 2017 
BRASIL. Ministério do Meio Ambiente. CONAMA. Resolução no 237/97. Disponível em: <http://www.mma.gov.br/port/conama/res/res97/res23797.html>. Acesso em: 20 de maio de 2015.

BRASIL. Ministério do Meio Ambiente. CONAMA. Resoluçãono ${ }^{\circ}$ 001/86. Disponível em:<http://www.mma.gov.br/port/conama/res/res86/res0186.html>. Acesso em: 20 de maio de 2015.

BRASIL. Súmula 7. Superior Tribunal de Justiça. Disponível em: < http://www.stj.jus.br/docs_internet/VerbetesSTJ_asc.pdf>. Acesso em: 15 de maio de 2015.

CARVALHO, Salo de. Como (não) se faz um trabalho de conclusão: provocações úteis para orientadores e estudantes de direito. 2. ed. São Paulo: Saraiva, 2013.

CAUBET, Christian Guy. O conceito de sociedade de risco como autoabsolvição das sociedades industriais infensas à responsabilidade jurídica. Cadernos de Direito, Piracicaba, v. 13(24): 6384, jan.-jun. 2013.

DECLARAÇÃO DO RIO SOBRE MEIO AMBIENTE. Disponível em: <http://www.mma.gov.br/port/sdi/ea/documentos/convs/decl_rio92.pdf>. Acesso em: 03/09/2016.

DEFICIÊNCIAS EM ESTUDOS DE IMPACTO AMBIENTAL: síntese de uma experiência. Brasília: Ministério Público Federal, $4^{\mathrm{a}}$ Câmara de Coordenação e Revisão: Escola Superior do Ministério Público da União, 2004. Disponível em: http://escola.mpu.mp.br/linhaeditorial/outras-publicacoes/impacto_ambiental3.pdf, acesso em 04/09/2016.

MACHADO, Paulo Affonso Leme. Direito Ambiental Brasileiro. 21. ed. São Paulo: Malheiros, 2013.

MILARÉ, Édis. Direito do Ambiente. 9. ed. São Paulo: Revista dos Tribunais, 2014.

MORAES, Fausto Santos de. Hermenêutica e Pretensão de Correção: Uma revisão crítica da aplicação do princípio da proporcionalidade pelo Supremo Tribunal Federal. 2013. 346f. Tese de doutoramento em Direito. São Leopoldo: UNISINOS, 2013.

NOVAES, Maikon R. de; RUDORFF, Bernardo F. T; ALMEIDA, Cláudia M. de; AGUIAR, Daniel A. de. Análise espacial da redução da queima na colheita da cana-de-açúcar: perspectivas futuras ao cumprimento do protocolo agroambiental. Eng. Agríc. 2011, vol.31, n.3, p. 572-583. Disponível em: < http://www.scielo.br/scielo.php?script=sci_arttext\&pid=S010069162011000300017>. Acesso em: 28 de abril de 2015.

SANDS, Phillipe. O Princípio da Precaução. In: PLATIAU, Ana Flávia Barros; VARELLA, Marcelo Dias (Org). Princípio da Precaução (Coleção Direito Ambiental em Debate). Editora Del Rey e Escola Superior do Ministério Público da União, s/d. Disponível em: <http://www.marcelodvarella.org/meio-ambienteriscos.html>. Acesso em: 03/09/2016. 
SARLET, Ingo Wolfgang; FENSTERSEIFER, Tiago. Direito Constitucional Ambiental: Constituição, Direitos Fundamentais e Proteção do Ambiente. 4. ed. São Paulo: Revista dos Tribunais, 2014.

SILVA, Solange Teles da. Princípio da Precaução: uma nova postura face aos riscos e as incertezas científicas. In: PLATIAU, Ana Flávia Barros; VARELLA, Marcelo Dias (Org.). Princípio da Precaução (Coleção Direito Ambiental em Debate). Editora Del Rey e Escola Superior do Ministério Público da União, s/d. Disponível em:

<http://www.marcelodvarella.org/meio-ambienteriscos.html>. Acesso em: 03/09/2016.

SILVEIRA, Clóvis Eduardo Malinverni da. Políticas públicas e processos decisórios em matéria de biossegurança à luz do princípio de precaução. In: LEITE, José Rubens Morato; PERALTA, Carlos E. (Org.). Perspectivas e desafios para a proteção da biodiversidade no Brasil e na Costa Rica. São Paulo: Instituto o Direito por um Planeta Verde, 2014, p. 342-365.

SILVEIRA, Clóvis Eduardo Malinverni da. Risco Ecológico Abusivo: a tutela do patrimônio ambiental nos Processos Coletivos em face do risco socialmente intolerável. Caxias do Sul: EDUCS, 2014.

WEDY, Gabriel de Jesus Tedesco. Os Fundamentos do Princípio da Precaução. Juris Plenum Direito Administrativo. Ano II, número 08, out/dez 2015, p. 109-138.

WEDY, Gabriel. O Princípio Constitucional da Precaução: Como instrumento de tutela do meio ambiente e da saúde pública. Belo Horizonte: Fórum, 2009. 